\title{
OSW-1 Induced Apoptosis in Hepatocellular Carcinoma through Generation of ROS, Cytochrome $C$ and Noxa Activation Independent of p53 with Non-Activation of Caspase-3
}

\author{
Xiaochen Liu, Jingchao Liang, Jichun Jin, Haiyang Li, Bosheng Mei, Xinglin Jin* \\ Department of Hepatopancreatobiliary Surgery, Affiliated Hospital of Yanbian University, Yanji, China \\ Email: *xljinyj@163.com
}

How to cite this paper: Liu, X.C., Liang, J.C., Jin, J.C., Li, H.Y., Mei, B.S. and Jin, X.L. (2017) OSW-1 Induced Apoptosis in Hepatocellular Carcinoma through Generation of ROS, Cytochrome $\mathrm{C}$ and Noxa Activation Independent of p53 with NonActivation of Caspase-3. Chinese Medicine, 8, 1-9.

https://doi.org/10.4236/cm.2017.81001

Received: January 22, 2017

Accepted: March 11, 2017

Published: March 14, 2017

Copyright $\odot 2017$ by authors and Scientific Research Publishing Inc. This work is licensed under the Creative Commons Attribution International License (CC BY 4.0).

http://creativecommons.org/licenses/by/4.0/

\begin{abstract}
Aim: To study the antitumor mechanism of OSW-1 in hepatocellular carcinoma. Materials and Methods: The expression profiling microarray was carried out to extract RNA from SK-Hep-1 which suffered from OSW-1. $\rho^{0}$-SK-Hep- 1 was maintained SK-Hep- 1 in MEM containing $100 \mu \mathrm{g} / \mathrm{L}$ ethidium bromide (EB), $1 \mathrm{mM}$ sodium pyruvate and $50 \mu \mathrm{g} / \mathrm{ml}$ uridine for 40 days. Then confirmed COX-I and COX-II of mitochondrial DNA were knocked out. Cells suffered from OSW-1 or doxorubicin. Then cells were washed twice with cold PBS and incubated with DCFH-DA. Fluorescent signal was recorded by using Infinite 200 Pro multimode Plate readers. Results: OSW-1 elevates generation of ROS and Cytochrome $\mathrm{C}$ which are associated with the induction of apoptosis in SK-Hep-1 cells. We also demonstrate that OSW-1 does not depend on p53 to up-regulate the BH3-only protein Noxa. What is more noteworthy that the Caspase- 9 and FADD are down-regulated in above process. Conclusion: OSW-1 induced special apoptosis is different from the mitochondrial death pathway and the death receptor pathway and final result is not Caspase family's activating. This provides a novel theory that nonmalignant cells are significantly less sensitive to OSW-1 than cancer cell lines.
\end{abstract}

\section{Keywords}

OSW-1, Hepatocellular Carcinomas, ROS, Cytochrome C, Mitochondrial Death Pathway

\section{Introduction}

$3 \beta, 16 \beta, 17 \alpha$-trihydroxycholest-5-en-22-one16-O-(2-O-4-methoxybenzoyl- $\beta$-Dxylopyranosyl)-( $1 \rightarrow 3)-(2-\mathrm{O}$-acetyl- $\alpha$-L-arabinopyranoside) (OSW-1) is found in 
the bulbs of Ornithogalum saudersiae and its antitumor activity is great at the nanomolar concentrations [1]. Its anticancer effect is 10 - 100 times that of Doxorubicin, Camptothecin and paclitaxel [2]. Nonmalignant cells were significantly less sensitive to OSW-1 than cancer cell lines, with concentrations that cause a $50 \%$ loss of cell viability, 40 - 150-fold greater than those observed in malignant cells. What's more, OSW-1 can lead to the loss of mitochondrial transmembrane potential, increase of cytosolic calcium, and activation of calcium-dependent apoptosis in both human leukemia and pancreatic cancer cells [3]. OSW-1-induced cell death indicates the important role of mitochondria in mediating the cytotoxic activity [4]. The anticancer activity exerted by OSW-1 is complex and the exact mechanisms responsible for such selectivity remain unclear though its total chemical synthesis was accomplished subsequently in 1999 [5]. To investigate the apoptosis mechanism of this unnaturally anticancer compound, we make a series of laboratory detection on hepatocellular carcinoma cells that were incubated with OSW-1 in vitro.

\section{Materials and Methods}

Cell cultures: SK-Hep-1 was obtained from the Chinese Academy of Sciences Cell Bank and the cell line was maintained in MEM media supplemented with $10 \%$ FBS. Monoclonal cell line was acquired by limiting dilution assay. Humidified incubator was set at $37^{\circ} \mathrm{C}, 5 \% \mathrm{CO}_{2} . \rho^{0}$-SK-Hep-1, mtDNA-less $\left(\rho^{0}\right)$ cell, was maintained SK-Hep-1 in MEM containing 10\% FBS, $100 \mathrm{IU} / \mathrm{ml}$ penicillin-streptomycin, $100 \mu \mathrm{g} / \mathrm{L}$ ethidium bromide (EB), $1 \mathrm{mM}$ sodium pyruvate and $50 \mu \mathrm{g} /$ $\mathrm{ml}$ uridine for 40 days. Then $\rho^{0}$-SK-Hep-1 was maintained in the culture solution without $\mathrm{EB}$.

$R N A$ isolation: We used $7 \times 10^{6}$ monoclonal cell for total RNA isolation. Total RNA was isolated by TRIzoL Reagent according to the manufacturer's instructions. The RNA concentration and purity were determined by absorbance at 260 $\mathrm{nm}$ the OD260/OD280 ratio using a NanoDrop ND1000 spectrophotometer. Then the RNA was isolated by eletrophoresis on formaldehyde denaturation agarose gel.

cDNA labeling Synthesis and Labeling. $10 \mu \mathrm{g}$ of the appropriate RNA was processed and labeled per the standard NimbleGen protocol. Briefly, RNA was converted into cDNA using Superscript Double-Stranded cDNA Synthesis Kit (Invitrogen, Carlsbad, CA). Double-stranded cDNA was random-prime labeled with Cy3 converted via oligo-dT by NimbleGen One-Color DNA Labeling Kit after cDNA Precipitation and RNase A Cleanup respectively.

Expression profiling using microarray. The Labelled cRNAs were hybridized to the NimbleGen Human Gene Expression $12 \times 135 \mathrm{~K}$ microarray as the following steps: 1) Reverse transcription with by Invitrogen Superscript ds-cDNA synthesis kit; 2) ds-cDNA labeling with NimbleGen one-color DNA labeling kit; 3) Array hybridization using the NimbleGen Hybridization System and followed by washing with the NimbleGen wash buffer kit; 4) Array scanning using the Axon GenePix 4000B microarray scanner. 
Data Analysis: Data were extracted and normalized using NimbleScan v2.5 Software. Raw signal intensities were normalized in RMA method by NimbleScan v2.5, and low intensity genes were filtered (Genes that at least 2 out of 2 samples have values $\geq$ lower cut-off: 50.0 were chosen for further analysis). Assess the quality of gene data after filtering by Box Plot and Scatter Plot. Then, differentially expressed genes that passed Fold Change filtering (Fold Change $\geq$ 2.0) and the final data were used to heat map then finished the hierarchical clustering, Pathway analysis (Figure 1).

Determination of intracellular reactive oxygen species (ROS): The level of intracellular ROS was determined on the basis of the oxidative conversion of cellpermeable 2',70'-dichlorofluorescein diacetate (DCFH-DA) to fluorescent dichlorofluorescein (DCF) upon reaction with hydroxyl radical, hydrogenperoxide, or peroxynitrite. Briefly, cells in $35 \mathrm{~mm}$ petri dishes were incubated with control media or $100 \mu \mathrm{g} / \mathrm{L}$ OSW-1 for $6 \mathrm{~h}$. Then cells were washed twice with cold PBS ( $\mathrm{pH}$ 7.4) and incubated with DCFH-DA 30 min in dark. Fluorescent signal was recorded by using Infinite 200 Pro multimode Plate readers. Three parallel experiments were performed. Results were shown as the mean value.

Detection of COX-I and COX-II by PCR amplification: To detect $\rho^{0}$-SK-Hep1 completely lacking mtDNA, using COX-I upstream primer (5'-ACACGAGCATATTTCACCTCCG-3'), downstream primer (5'-GGATTTTGGCGTAGGTTTGGTC-3') and COX-II upstream primer (5'-ATCAAATCAATTGGCCACCAATGGTA-3'), downstream primer (5'-TTGACCGTAGTATACCCCCGGTC$\left.3^{\prime}\right)$. The PCR conditions were as follows: $94^{\circ} \mathrm{C}$ for $30 \mathrm{~s}, 55^{\circ} \mathrm{C}$ for $30 \mathrm{~s}$, and $72^{\circ} \mathrm{C}$ for $60 \mathrm{~s}\left(35 \mathrm{cycles}\right.$ ) and a final extension at $72^{\circ} \mathrm{C}$ for $10 \mathrm{~min}$. the result was detected by agarose gel electrophoresis.

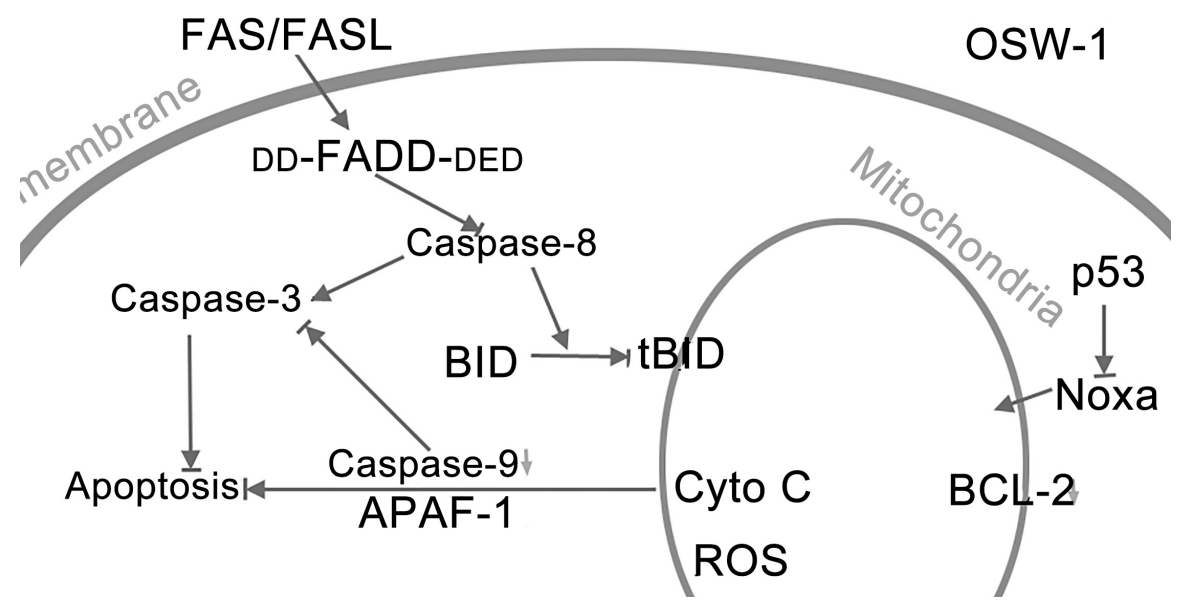

Figure 1. Differentially expressed genes between SK-Hep-1 treated by OSW-1 and control group were identified through Fold Change filtering. Pathway analysis was applied to determine the roles of these differentially expressed genes played in these biological pathways. $\longrightarrow$ means upstream genes don't effect the expression of downstream genes. Such as Noxa wasn't be affected by p53. means its expression was down-regulated. Such as Caspase- 9 was down-regulated by OSW-1. 
Statistical analysis: All values are presented as the mean \pm SEM. All data were analyzed using one-way ANOVA followed by post-hoc LSD multiple comparisons or the independent-samples t-test using SPSS version 13.0 (SPSS, Inc., Chicago, IL, USA). $\mathrm{P}<0.05$ was considered to indicate a statistically significant difference.

\section{Result}

Expression data were normalized through quantile normalization and the Robust Multichip Average algorithm, the gene level were generated after normalization. Differentially expressed genes between two groups were identified through Fold Change filtering. The expression of Fas-associating protein with a novel death domain (FADD), Cytochrome C and Noxa in SK-Hep-1 cells were inhibited by OSW-1 as determined by gene expression profiling. At the same time, Caspase-8, Caspase- 9 and Bid were activated by OSW-1 that compared with control group (Figure 2).

Pathway Analysis was applied to determine the roles of these differentially expressed genes played (Figure 1). Suffered from OSW-1, Caspase-8 didn't downregulate as FADD was down-regulating. Noxa was obviously activated, though P53 had no significant difference between two groups. So with the cleavage of $\mathrm{Bcl}-2$, mitochondria apoptosis pathway was activated, and Cytochrome $\mathrm{C}$ and ROS were released from mitochondria into cytosol. But there was no activation of Caspase 3, and Caspase-9 was down-regulated.

Agarose gel electrophoresis shows COX-I and COX-II of mitochondrial DNA was knocked out in $\rho^{0}$-SK-Hep- 1 after the treatment of EB for 40 days and we can consider the cell model of deletion of mitochondrial DNA, $\rho^{0}$-SK-Hep-1, was successfully constructed (Figure 3 ). $\rho^{0}$-SK-Hep-1 released more ROS than
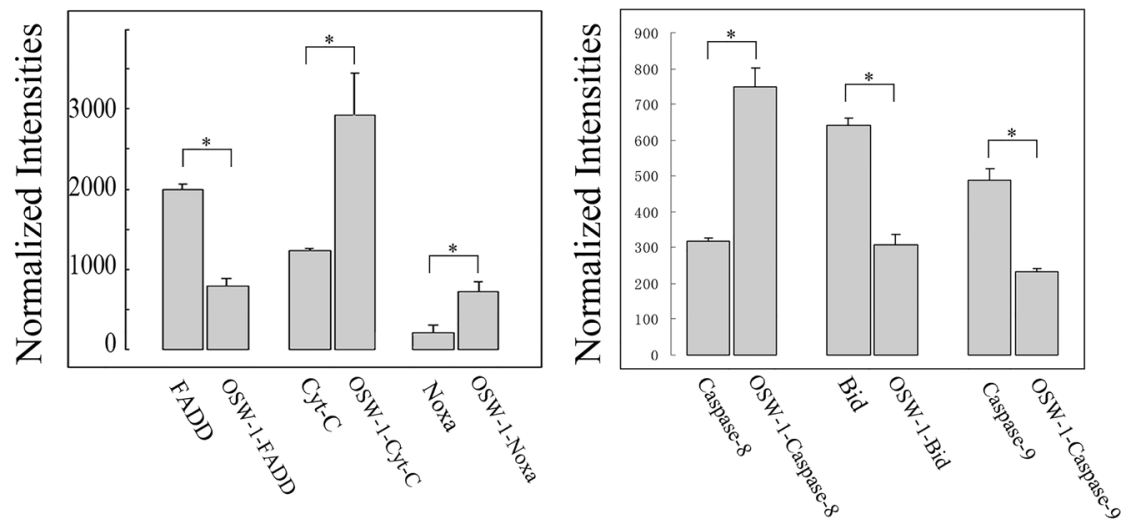

Figure 2. Total RNA was isolated from SK-Hep-1, which was treated with $200 \mathrm{ng} / \mathrm{ml}$ OSW-1 for 24 hours and control group. Total RNA from each group was quantified by the NanoDrop ND-1000 and RNA integrity was assessed by standard denaturing agarose gel electrophoresis. Then, the RNAs were used for labeling and array hybridization. After washing, slides were scanned with Axon Gene Pix 4000B scanner. Data were extracted and normalized using NimbleScan v2.5 Software. Raw signal intensities were normalized in RMA method by NimbleScan v2.5, and low intensity genes were filtered. ${ }^{\star} \mathrm{P}<0.01$ as compared to the control group. 
SK-Hep-1 in normal growth and the deletion of mitochondrial DNA reduced the two's drug sensitivity. But OSW-1 and doxorubicin still affected the release of ROS through concentration and time (Figure 4).

Figure 2 Total RNA was isolated from SK-Hep-1, which was treated with 200 $\mathrm{ng} / \mathrm{ml}$ OSW-1 for 24 hours and control group. Total RNA from each group was quantified by the NanoDrop ND-1000 and RNA integrity was assessed by standard denaturing agarose gel electrophoresis. Then, the RNAs were used for labeling and array hybridization. After washing, slides were scanned with Axon GenePix

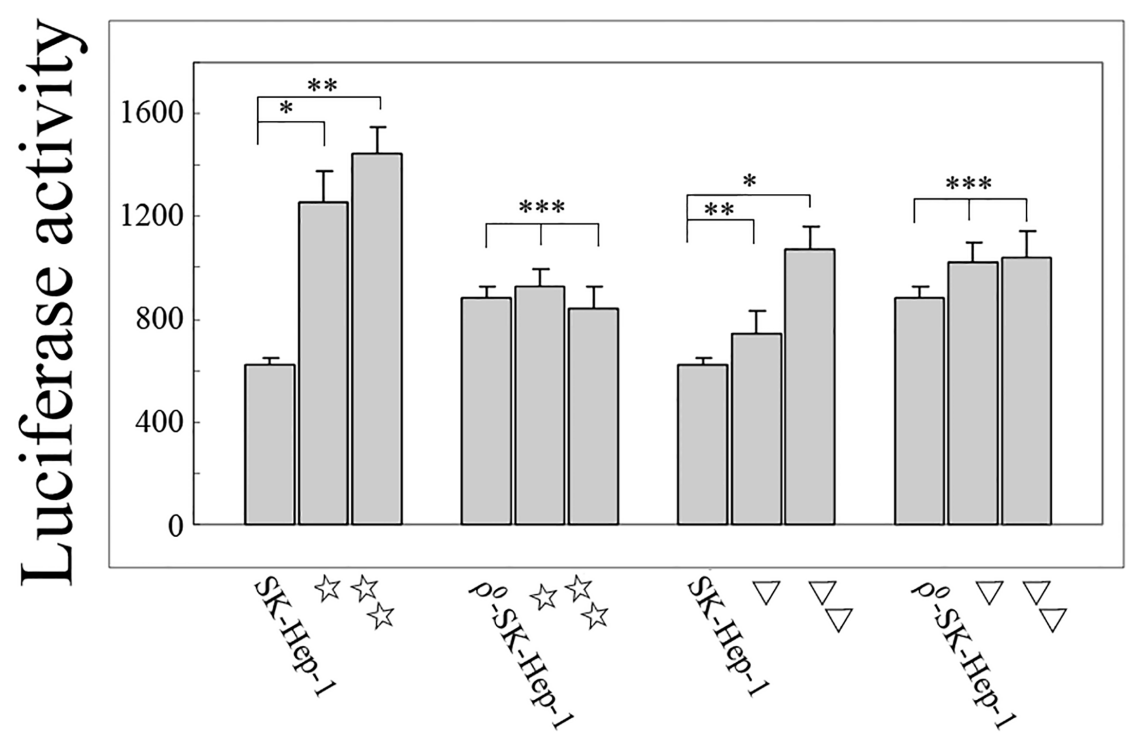

Figure 3. Intracellular ROS was detected by means of an oxidation-sensitive fluorescent probe (DCFH-DA). After treatment with OSW-1 $100 \mathrm{ng} / \mathrm{ml}$ (论) and $200 \mathrm{ng} / \mathrm{ml}$ (论㑔) for $6 \mathrm{~h}$. As the control group, we mad doxorubicin $200 \mathrm{ng} / \mathrm{ml}(\triangle)$ and $400 \mathrm{ng} / \mathrm{ml}(\Delta \Delta)$ treat $\rho^{0}$-SK-Hep-1 and SK-Hep-1 with the same time. Fluorescent signal was recorded by using Infinite 200 Pro multimode Plate readers. ${ }^{*} \mathrm{P}<0.05$ as compared to the control group. ${ }^{\star *} \mathrm{P}<0.01$ as compared to the control group. ${ }^{\star * *} \mathrm{P}>0.05$ as compared to the control group.

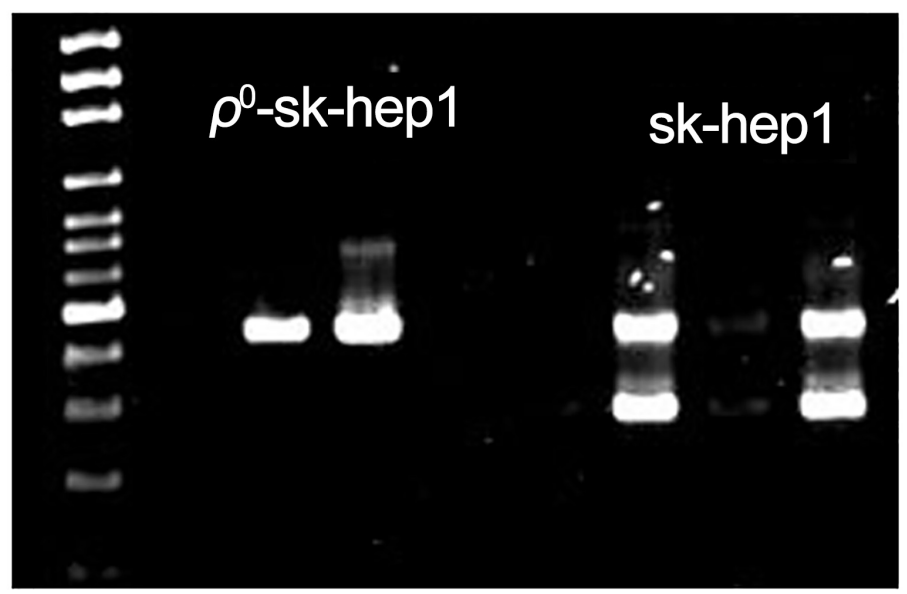

Figure 4. Agarose gel electrophoresis shows that COX-I and COX-II were knocked out in $\rho^{0}$-SK-Hep-1 after the treatment of EB for 40 days. G3PDH is the internal reference in this detection. 
4000B scanner. Data were extracted and normalized using NimbleScan v2.5 Software. Raw signal intensities were normalized in RMA method by NimbleScan v2.5, and low intensity genes were filtered. ${ }^{\star} \mathrm{P}<0.01$ as compared to the control group.

\section{Discussion}

As the energy factory of cell, mitochondrion is the basic of the survival of eukaryotic cell. More and more studies provide evidence that it's the activation centre of cell apoptosis [6]. In the process of apoptosis, several pro-apoptotic proteins transfer to outer mitochondrial membrane, and it leads permeability and integrity of mitochondria destroyed. Extinction of membrane potential will appear when a sufficient number of hydrion flows into mitochondria and the open of permeability transition pore (PTP). A lot of apoptosis inducing factors released from the mitochondria to participate the classical apoptosis process, include Cytochrome C [7], apoptosis-inducing factor (AIF) [8], and Caspase-2, -3, -8, -9 and so on [9]. It is generally accepted that the process of apoptosis involves two pathways: the mitochondrial death pathway and the death receptor pathway, and they have cross-talk with each other. Caspase- 8 , which cleaves Bid to tBid, is activated by Fas-associated protein with death domain (FADD) binding to ligand to release Cytochrome $\mathrm{C}[10]$. OSW-1 is capable of inducing apoptosis in mammalian cells, in which the Caspase-8-dependent cleavage of Bcl-2 plays an important role [11]. As the same time, Caspase- 8 is up-regulated by OSW-1, cleavage of Bcl-2; down-regulation of Bid is observed and a large amount of Cytochrome $\mathrm{C}$ release from cytosol (Figure 2). It's strangely that the release of Cytochrome C, which marks the mitochondrial apoptotic pathway, doesn't lead to the activation of the Caspase-9 and the Caspase-3 (Figure 2). So, we expand our attention to FADD and Cytochrome $\mathrm{C}$ in mitochondrial apoptosis pathway. The accumulation of FADD and procaspase- 8 in the death-inducing signaling complex (DISC) generates active Caspase-8, which is released from the complex to activate the executioner Caspase [12]. OSW-1 exactly promotes this process, under the conditions of down-regulation of FADD. Caspase- 8 cleaves Bid and the loss of integrity of the mitochondrial membrane makes the release of Cytochrome C (Figure 2). Taken together, OSW-1 crosses the death receptor pathway and makes the loss of integrity of mitochondrial membrane, but it doesn't activate the apoptosis induced by Caspase-family (Figure 1).

When the classic apoptosis pathway cannot provide a full explanation, we create a diversion to another important regulator for mitochondrial membrane. As the balancer of the glycolysis pathway and mitochondrial oxidative phosphorylation function [13], p53-induced glycolysis and apoptosis-regulator (TIGAR) and synthesis of Cytochrome $\mathrm{C}$ oxidase 2 (SCO2) are critical for this balance. TIGAR reduces the expression of fructose 2,6 diphosphate to inhibit glycolysis and promote the generation of NADPH [14]. p53 regulates BCL-2 homeodomain proteins, up-regulate Puma and Noxa and activate Bax to promote permeabilization of outer mitochondrial membrane in the process of apoptosis [15] 
[16]. Noxa encodes a Bcl-2 homology 3 (BH3)-only member of the Bcl-2 family of proteins. This member contains the $\mathrm{BH} 3$ region but not other $\mathrm{BH}$ domains, whose expression was mainly regulated by p53. p53 induced apoptosis still perform the same phenomenon that OSW-1 activates Noxa overleapt p53 (Figure 1, Figure 2). Gene expression microarray analysis, revealed marked up-regulation of the BH3-only protein Noxa, after OSW-1 addition, independent of p53 status. Bcl-2-like proteins and vBcl-2 proteins are potent inhibitors of apoptosis and $\mathrm{vBcl}-2$ played a role in inhibiting apoptosis by NOXA. The Bcl2 homology domain 3 (BH3)-only protein Noxa is at the tip of the balance between life and death and appears to be crucial for cell death along the mitochondrial Bcl2-regulated apoptosis pathway [17] [18]. So, it has reason to believe that OSW-1 activated the mitochondria death pathway through NOXA-dependent cleavage of Bcl-2 and vBcl-2 but p53.

Although the apoptosis was not induced by Caspase-family and p53 pathway, the apotosis did happen [19]. To elucidate and confirm the molecular mechanism by which OSW-1 induces apoptosis in hepatoma carcinoma cell (HCC), to determine OSW-1 induced apoptosis through mitochondrial DNA (mtDNA) and proteins, the generation of ROS from the depletion of mtDNA of cell $\left(\rho^{0}\right.$ SK-Hep-1) were analyzed (Figure 3). Compare with the SK-Hep-1's ROS, $\rho^{0}$ SK-Hep-1 has a higher level of generation, and OSW-1 induced the generation of SK-Hep-1 in a concentration manner, but $\rho^{0}$-SK-Hep-1. At the same time, doxorubicin still induced generation of ROS a certain extent in $\rho^{0}$-SK-Hep- 1 cell line. There is no expression of mitochondria-encoded respiratory complex subunits COX-1, COX-2 in $\rho^{0}$-SK-Hep-1 (Figure 4). So it suggests that OSW-1 induced directive apoptosis through mtDNA and the protein mtDNA encoded. Jeong's study showed that upon FR122047 treatment, the selective COX-1 inhibitor, there were apparent increases in the ratio of $\mathrm{Bax}$ to $\mathrm{Bcl}-2$, mitochondrial Cytochrome $\mathrm{C}$ release, and apoptosis in MCF-7 cells [20]. It has reason to consider OSW-1 induced apoptosis through COX-1 not Caspase-family and p53 pathway. For all that, the immediate evidence that the apoptosis, OSW-1 induced, Noxa activation independent of p53 with nonactivation of Caspase-family and ROS, Cytochrome $\mathrm{C}$ went in mass production.

\section{References}

[1] Kubo, S., Mimaki, Y., Terao, M., Sashida, Y., Nikaido, T. and Ohmoto, T. (1992) Acylated Cholestane Glycosides from the Bulbs of Ornithogalum saudersiae. Phytochemistry, 31, 3969-3973. https://doi.org/10.1016/S0031-9422(00)97565-4

[2] Mimaki, Y., Kuroda, M., Kameyama, A., Sashida, Y., Hirano, T. and Oka, K. (1997) Cholestane Glycosides with Potent Cytostatic Activities on Various Tumor Cells from Ornithogalum saundersiae Bulls. Bioorganic \& Medicinal Chemistry Letters, 7, 633-636. https://doi.org/10.1016/S0960-894X(97)00071-1

[3] Zhou, Y., Garcia-Prieto, C., Carney, D.A., Xu, R.H., Pelicano, H., Kang, Y., Yu, W., Lou, C., Kondo, S., Liu, J., Harris, D.M., Estrov, Z., Keating, M.J., Jin, Z. and Huang, P. (2005) OSW-1: A Natural Compound with Potent Anticancer Activity and a Novel Mechanism of Action. Journal of the National Cancer Institute, 97, 17811785. https://doi.org/10.1093/jnci/dji404 
[4] Garcia-Prieto, C., Riaz Ahmed, K.B., Chen, Z., Zhou, Y., Hammoudi, N., Kang, Y., Lou, C., Mei, Y., Jin, Z. and Huang, P. (2013) Effective Killing of Leukemia Cells by the Natural Product OSW-1 through Disruptio of Cellular Calcium Homeostasis. Journal of Biological Chemistry, 288, 3240-3250. https://doi.org/10.1074/jbc.M112.384776

[5] Deng, S., Yu, B., Lou, Y. and Hui, Y. (1999) First Total Synthesis of an Exceptionally Opymy Antitumoer Saponin, OSW-1. The Journal of Organic Chemistry, 64, 202208. https://doi.org/10.1021/jo981685c

[6] Desagher, S. and Martinou, J.C. (2000) Mitochondria as the Central Control Point of Apoptosis. Trends in Cell Biology, 10, 369-377. https://doi.org/10.1016/S0962-8924(00)01803-1

[7] Liu, X., Kim, C.N., Yang, J., Jemmerson, R. and Wang, X. (1996) Induction of Apoptotic Program in Cell-Free Extracts: Requirement for dATP and Cytochrome C. Cell, 86, 147-157. https://doi.org/10.1016/S0092-8674(00)80085-9

[8] Lorenzo, H.K., Susin, S.A., Penninger, J. and Kroemer, G. (1999) Apoptosis Inducing Factor (AIF): A Phylogenetically Old, Caspase-Independent Effector of Cell Death. Cell Death and Differentiation, 6, 516-524. https://doi.org/10.1038/sj.cdd.4400527

[9] Mancini, M., Nicholson, D.W., Roy, S., Thornberry, N.A., Peterson, E.P., Casciola-Rosen, L.A. and Rosen, A. (1998) The Caspase-3 Precursor Has a Cytosolic and Mitochondrial Distribution: Implications for Apoptotic Signaling. The Journal of Cell Biology, 140, 1485-1495. https://doi.org/10.1083/jcb.140.6.1485

[10] Li, H., Zhu, H., Xu, C.J. and Yuan, J. (1998) Cleavage of BID by Caspase 8 Mediates the Mitochondrial Damage in the Fas Pathway of Apoptosis. Cell, 94, 491-501. https://doi.org/10.1016/S0092-8674(00)81590-1

[11] Zhu, J., Xiong, L., Yu, B. and Wu, J. (2005) Apoptosis Induced by a New Member of Saponin Family Is Mediated through Caspase-8-Dependent Cleavage of Bcl-2. Molecular Pharmacology, 68, 1831-1838. https://doi.org/10.1124/mol.105.015826

[12] Von Haefen, C., Wendt, J., Semini, G., Sifringer, M., Belka, C., Radetzki, S., Reutter, W., Daniel, P.T. and Danker, K. (2011) Synthetic Glycosidated Phospholipids Induce Apoptosis through Activation of FADD, Caspase- 8 and the Mitochondrial Death Pathway. Apoptosis, 16, 636-651. https://doi.org/10.1007/s10495-011-0592-2

[13] Matoba, S., Kang, J.G., Patino, W.D., Wragg, A., Boehm, M., Gavrilova, O., Hurley, P.J., Bunz, F. and Hwang, P.M. (2006) p53 Regulates Mitochondrial Respiration. Science, 312, 1650-1653. https://doi.org/10.1126/science.1126863

[14] Bensaad, K., Tsuruta, A., Selak, M.A., Vidal, M.N., Nakano, K., Bartrons, R., Gottlieb, E. and Vousden, K.H. (2006) TIGAR, a p53-Inducible Regulator of Glycolysis and Apoptosis. Cell, 126, 107-120. https://doi.org/10.1016/j.cell.2006.05.036

[15] Villunger, A., Michalak, E.M., Coultas, L., Müllauer, F., Böck, G., Ausserlechner, M.J., Adams, J.M. and Strasser, A. (2003) p53- and Drug-Induced Apoptotic Responses Mediated by BH3-Only Proteins Puma and Noxa. Science, 302, 1036-1038. https://doi.org/10.1126/science.1090072

[16] Chipuk, J.E., Kuwana, T., Bouchier-Hayes, L., Droin, N.M., Newmeyer, D.D., Schuler, M. and Green, D.R. (2004) Direct Activation of Bax by p53 Mediates Mitochondrial Membrane Permeabilization and Apoptosis. Science, 303, 1010-1014. https://doi.org/10.1126/science.1092734

[17] Okamoto, T., Campbell, S., Mehta, N., Thibault, J., Colman, P.M., Barry, M., Huang, D.C. and Kvansakul, M. (2012) Sheeppox Virus SPPV14 Encodes a Bcl-2Like Cell Death Inhibitor That Counters a Distinct Set of Mammalian Proapoptotic Proteins. Journal of Virology, 86, 11501-11511. 
https://doi.org/10.1128/JVI.01115-12

[18] Ploner, C., Kofler, R. and Villunger. A. (2008) Noxa: At the Tip of the Balance between Life and Death. Oncogene, 27, S84-S92. https://doi.org/10.1038/onc.2009.46

[19] Jin, J., Jin, X., Qian, C., Ruan, Y. and Jiang, H. (2013) Signaling Network of OSW1-Induced Apoptosis and Necroptosis in Hepatocellular Carcinoma. Molecular Medicine Reports, 7, 1646-1650. https://doi.org/10.3892/mmr.2013.1366

[20] Jeong, H.S., Kim, J.H., Choi, H.Y., Lee, E.R. and Cho, S.G. (2010) Induction of Cell Growth Arrest and Apoptotic Cell Death in Human Breast Cancer MCF-7 Cells by the COX-1 Inhibitor FR122047. Oncology Reports, 24, 351-356.

Submit or recommend next manuscript to SCIRP and we will provide best service for you:

Accepting pre-submission inquiries through Email, Facebook, LinkedIn, Twitter, etc. A wide selection of journals (inclusive of 9 subjects, more than 200 journals)

Providing 24-hour high-quality service

User-friendly online submission system

Fair and swift peer-review system

Efficient typesetting and proofreading procedure

Display of the result of downloads and visits, as well as the number of cited articles

Maximum dissemination of your research work

Submit your manuscript at: http://papersubmission.scirp.org/

Or contact cm@scirp.org 